\title{
Impact of Prostaglandin and Thromboxane Synthesis Blockade on Disposition of Group B Streptococcus in Lung and Liver of Intact Piglet
}

\author{
THOMAS H. PAULY, SHEWAN M. AZIZ, SANDRA J. HORSTMAN, AND MARK N. GILLESPIE \\ Department of Pediatrics, Division of Neonatology, College of Medicine [T.H.P., M.N.G.] and Division of \\ Pharmacology and Experimental Therapeutics, College of Pharmacy [S.M.A., S.J.H., M.N.G.J, University of \\ Kentucky A. B. Chandler Medical Center, Lexington, Kentucky 40536-0082
}

\begin{abstract}
Group B streptococci (GBS) localizing in the lungs of infant piglets is killed in part by an oxygen radicaldependent mechanism (Bowdy BD, Marple SL, Pauly TH, Coonrod JD, Gillespie MN: Am Rev Respir Dis 141:648$653,1990)$. The source of bactericidal oxygen radicals is unknown, but cyclooxygenation of arachidonic acid, an initial event in prostanoid synthesis, is accompanied by substantial oxygen radical generation. Because blockade of prostaglandin H synthase (cyclooxygenase) with indomethacin prevents GBS-induced pulmonary hypertension, we reasoned that the salutary effect of indomethacin might be associated with a reduction in the efficacy of bactericidal activity directed against GBS. To address this possibility, the distribution and viability of ${ }^{111}$ In-labeled GBS $\left(10^{8}\right.$ colony forming units $/ \mathrm{kg} / \mathrm{min}$ i.v. for $15 \mathrm{~min}$ ) were assessed in lungs and livers of control piglets, piglets treated with indomethacin $(1 \mathrm{mg} / \mathrm{kg})$, and piglets treated with $\mathrm{OKY}-$ $046(10 \mathrm{mg} / \mathrm{kg})$, an inhibitor of thromboxane synthase that also forestalls GBS-induced pulmonary hypertension. Relative to control animals, indomethacin treatment increased pulmonary GBS uptake with no change in bacterial distribution into the liver. OKY-046 failed to influence pulmonary bacterial uptake but promoted a substantial increase in GBS depositing in the liver. In contrast to its effects on pulmonary bacterial deposition, indomethacin failed to increase lung bacterial viability relative to control animals. Indomethacin also was without effect on hepatic bacterial viability. OKY-046 failed to influence pulmonary bacterial viability but markedly augmented hepatic GBS viability to the extent that significant bacterial proliferation occurred. Both indomethacin and OKY-046 abolished GBS-induced pulmonary hypertension by preventing the increase in pulmonary arterial pressure and decrease in cardiac output. Viewed collectively, these observations suggest that oxygen radicals derived from cyclooxygenation of arachidonic acid in GBS-treated piglets do not contribute to microbicidal activity directed against the organism. (Pediatr Res 31: 14-17, 1992)
\end{abstract}

\section{Abbreviations}

GBS, group B streptococci

HBSS, Hanks' balanced salt solution

cfu, colony forming units

Received January 28, 1991; accepted August 19, 1991.

Correspondence: Mark N. Gillespie, Ph.D., Division of Pharmacology and Experimental Therapeutics, College of Pharmacy, University of Kentucky A.B. Chandler Medical Center, Lexington, KY 40536-0082.

Supported in part by grants from the National Institutes of Health (HL-38495, HL-02055) and the American Heart Association, Kentucky Affiliate and National Center.
Ppa, pulmonary arterial pressure

Multiple lines of evidence indicate that cyclooxygenase products of arachidonic acid metabolism, particularly thromboxane $\mathrm{A}_{2}$, are important mediators of the early pulmonary hypertensive response to GBS sepsis. Blockade of prostaglandin $\mathrm{H}$ synthase (cyclooxygenase) with indomethacin or blockade of thromboxane synthase with dazmegrel forestalls increases in Ppa and pulmonary vascular resistance provoked by GBS in young piglets $(1,2)$. Thromboxane also accumulates in systemic blood after challenge with GBS or other gram-positive organisms (3). Administration of a thromboxane mimetic elevates Ppa in a manner similar to the response to GBS (4).

We have recently reported that a substantial proportion of intravascular GBS localizes in lung tissue, probably in pulmonary intravascular macrophages, where the organism is killed in part by an oxygen radical-dependent mechanism $(5,6)$. The cellular and biochemical sources of bactericidal oxygen radicals are unknown, but several pathways for oxygen radical generation within phagocytes have been described (7). In light of the probable role of eicosanoids in GBS-induced pulmonary hypertension, it is significant that bactericidal oxygen radicals are generated as a consequence of arachidonic acid metabolism (8). Cyclooxygenation of arachidonic acid via prostaglandin $H$ synthase has been shown to produce superoxide anion (9). The action of lipoxygenase on arachidonic acid also generates superoxide anion, but the rate of production is considerably lower than that associated with prostaglandin $H$ synthase (9). Finally, metabolism of arachidonic acid to epoxides by cytochrome P-450 generates superoxide anion (10), but virtually nothing is known of the kinetics and importance of this pathway.

Indomethacin and other nonsteroidal anti-inflammatory agents prevent superoxide anion generation secondary to the action of prostaglandin $\mathrm{H}$ synthase on arachidonic acid (8). To determine if oxygen radicals from this source contribute to pulmonary microbicidal activity directed against GBS, the present study tested the hypothesis that indomethacin increases viability of the organism. The impact of the thromboxane synthase inhibitor OKY -046 on pulmonary GBS disposition also was examined because blockade of arachidonic acid metabolism at this step in the pathway leaves intact the generation of bactericidal oxygen radicals (8) but prevents hemodynamic abnormalities evoked by GBS (2). In addition to addressing the source of microbicidal oxygen radicals, these experiments may have clinical implications; inasmuch as blockade of prostaglandin $\mathrm{H}$ synthase or thromboxane synthase may comprise a potential therapeutic approach to sepsis-related pulmonary hypertension (1-3), the possibility should be considered that along with suppressing development of pulmonary hypertension, such agents may also impair host bacterial defense. 


\section{MATERIALS AND METHODS}

Culture and preparation of ${ }^{111}$ In-labeled GBS. Cultures of GBS (Streptococcus agalactiae, serotype II, American-type Culture Collection no. 13813, Difco Laboratories, Detroit, MI) were inoculated in brain-heart infusion broth containing $7 \%$ heatinactivated $\mathrm{FCS}$ and grown to $\log$ phase at $37^{\circ} \mathrm{C}$ under a $5 \% \mathrm{CO}_{2}$ atmosphere. The medium was centrifuged at $2000 \times g$ for 15 min, and the pellet washed and resuspended in HBSS. Concentration of bacteria in the slurry was determined by quantitative culture and by relating OD to cfu. Procedures described previously were used to radiolabel the organisms with ${ }^{111}$ In $(5,6)$. In brief, GBS suspended in HBSS were centrifuged, the pellet was resuspended in HBSS, and $1 \mathrm{~mL}$ containing approximately 2.5 $\times 10^{10} \mathrm{cfu}$ was transferred to a microfuge tube and mixed with $15 \mu \mathrm{Ci}{ }^{11}$ In-oxine. The tube was vortexed three times at 5-min intervals and then centrifuged at $15000 \times g$ for $2 \mathrm{~min}$. The resulting pellet was resuspended in $1 \mathrm{~mL} \mathrm{HBSS}$. This procedure (vortexing, centrifugation, and resuspension) was repeated four times. After the $3 \mathrm{rd}$ cycle, bacteria were resuspended in $50 \mathrm{~mL}$ of medium (instead of $1 \mathrm{~mL}$ ) and allowed to stand at room temperature for $1.5 \mathrm{~h}$ to remove any remaining soluble or loosely adherent indium. After the last centrifugation, the pellet was resuspended in HBSS to a bacterial concentration $10^{9} \mathrm{cfu} / \mathrm{mL}$.

Animal preparation and experimental protocol. Piglets ranging in age from 5 to $10 \mathrm{~d}$ and in weight from 1.7 to $3.1 \mathrm{~kg}$ were anesthetized with $50 \mathrm{mg} / \mathrm{kg}$ sodium pentobarbital intraperitoneally and placed on a servo-controlled heat exchanging pad to maintain body temperature at $38 \pm 1^{\circ} \mathrm{C}$. A tracheal cannula was inserted and the animals were ventilated $\left(\mathrm{FiO}_{2}=0.3\right)$ with a Harvard small animal ventilator (Kent, England). A polyethylene catheter was inserted into the jugular vein and advanced into the pulmonary artery for monitoring of Ppa. Additional catheters were inserted into the femoral vein and artery for bacterial administration and for monitoring of systemic arterial pressure. Pressures were monitored using Statham transducers (Oxnard, $\mathrm{CA}$ ) in conjunction with a Grass model 7 polygraph (Quincy, MA). Cardiac output was measured in duplicate by thermodilution using an Edwards Laboratory (model 9250A, Santa Anna, $\mathrm{CA}$ ) cardiac output computer and a $5 \mathrm{~F}$ thermodilution catheter. Arterial blood gases in $1-\mathrm{mL}$ blood samples taken from the arterial catheter were determined using an Instrumentation Laboratories model 213 blood gas analyzer (Lexington, MA). During a $30-\mathrm{min}$ equilibration period, the ventilator was adjusted to attain baseline $\mathrm{PO}_{2}, \mathrm{PCO}_{2}$, and $\mathrm{pH}$ values of $15.33-13.34 \mathrm{kPa}$ (115-130 torr), 4.93-5.59 $\mathrm{kPa}$ (37-42 torr), and 7.35-7.45 $\mathrm{kPa}$, respectively. Ventilator settings were not changed after initiation of the experiment.

Animals were divided into three groups of five to seven, with each animal receiving a $15-\mathrm{min}$ i.v. infusion of $10^{8} \mathrm{cfu} \mathrm{GBS} / \mathrm{kg} /$ $\mathrm{min}$. One group served as the control and, $10 \mathrm{~min}$ before GBS, received an i.v. bolus injection of the vehicle for indomethacin, $100 \mathrm{mM}$ sodium carbonate. The second and third groups were treated identically, except that they received slow i.v. bolus injections (over approximately $5 \mathrm{~min}$ ) of $1 \mathrm{mg} / \mathrm{kg}$ indomethacin and $10 \mathrm{mg} / \mathrm{kg}$ OKY-046, respectively. Doses of indomethacin and OKY-046 were selected on the basis of reports in the literature documenting their efficacy to inhibit thromboxane synthesis $(4,11)$. The vehicle for OKY-046 was sterile saline; controls were not performed for this treatment group.

Assessment of bacterial deposition and viability. Animals were killed with an overdose of sodium pentobarbital 45 min after termination of the 15-min bacterial infusion. Lungs and liver were removed aseptically, weighed, and homogenized in 4-mL sterile HBSS. Radioactivity was determined in an aliquot of homogenate using a Packard gamma counter (Downers Grove, IL). Bacterial deposition was quantitated as the percentage of radioactivity distributing into a particular organ relative to the total amount of radioactivity recovered in the organs of interest. To assess bacterial viability, an aliquot of homogenate was serially diluted in HBSS, streaked on blood agar plates, and incubated for 24 to $48 \mathrm{~h}$ in $5 \% \mathrm{CO}_{2}$ at $37^{\circ}$. Bacterial colonies were counted and expressed as cfu per $g$ of tissue. The percentage of bacterial viability, determined according to methods previously described $(5,6,12)$, was calculated as: $100 \times\left[\left(\mathrm{cfu}_{t} / \mathrm{cpm}_{t}\right) \div\right.$ $\left.\left(\mathrm{cfu}_{i} / \mathrm{cpm}_{i}\right)\right]$ where $t$ refers to time after infusion and $i$ refers to the value for the uninfused GBS inoculum. This method normalizes the number of bacteria remaining viable to the total bacterial burden of the tissue.

Statistical analysis. Data are presented as the mean \pm SEM. Differences between experimental groups were assessed using a one- or two-way analysis of variance, depending on the variable measured, combined with Dunnett's test. Differences were considered significant when $p \leq 0.05$.

\section{RESULTS}

Time-dependent changes in mean Ppa, cardiac output, and arterial $\mathrm{PO}_{2}$ evoked by GBS in control piglets and in animals treated with indomethacin or OKY-046 are shown in Figure 1. As expected, GBS given to control animals caused prompt increases in mean Ppa, decreases in cardiac output, and decreases in arterial $\mathrm{PO}_{2}$. These changes tended to moderate on termination
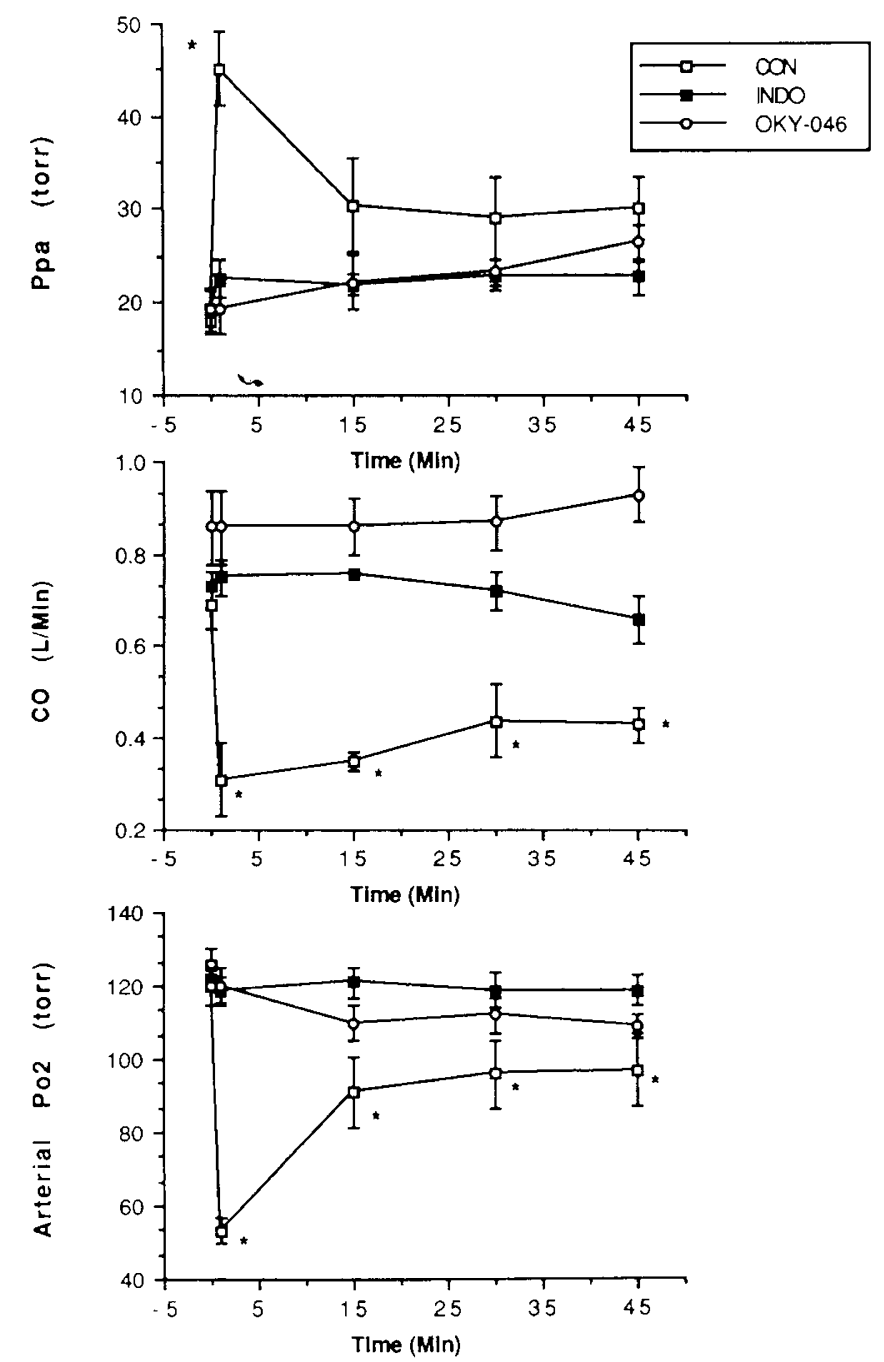

Fig. 1. Time-dependent changes in mean Ppa (top panel), cardiac output (middle panel), and arterial $\mathrm{PO}_{2}$ (bottom panel: arterial $\mathrm{PO}_{2}$ in $\mathrm{kPa}=$ arterial $\mathrm{PO}_{2}$ in torr $\left.\times 0.1333\right)$ evoked by GBS $\left(10^{8} \mathrm{cfu} / \mathrm{min} / \mathrm{kg}\right.$ from $t=0$ to $t=15 \mathrm{~min})$ in control piglets $(n=7)$, and in piglets pretreated with either indomethacin $(1 \mathrm{mg} / \mathrm{kg},(n=6)$ or OKY-046 $(10$ $\mathrm{mg} / \mathrm{kg}, n=5) .{ }^{*}=$ Significantly different from both drug-treated groups at $p<0.05$. 
of the 15-min GBS infusion but failed to return completely to baseline values within the 45 -min postinfusion period. Also as expected, both indomethacin and OKY-046 prevented the hypertensive response and decline in arterial $\mathrm{PO}_{2}$. Ppa failed to increase above baseline values, and cardiac output did not fall in either drug-treated group.

The impact of indomethacin and OKY-046 on distribution of GBS into the lungs and liver is shown in Figure 2. Relative to control animals, indomethacin treatment was associated with an increase in pulmonary GBS uptake with no change in bacterial distribution into the liver. OKY-046 failed to influence pulmonary bacterial uptake but promoted a substantial increase in GBS depositing in the liver.

Figure 3 illustrates the effects of indomethacin and OKY-046 on bacterial viability in the lungs and liver. In contrast to our hypothesis, indomethacin failed to increase bacterial viability in the lung relative to control animals. Conversely, a trend $(0.1>$ $p>0.05)$ toward decreased pulmonary bacterial viability was noted. Bacterial viability in the liver was unaffected by indomethacin treatment. OKY-046 also failed to increase pulmonary bacterial viability, although a trend toward this response was evident. In contrast, hepatic GBS viability was markedly increased by OKY-046, to the extent that significant bacterial proliferation was observed.

\section{DISCUSSION}

The present study tested the hypothesis that indomethacin, an inhibitor of prostaglandin $\mathrm{H}$ synthase known to prevent sepsis-
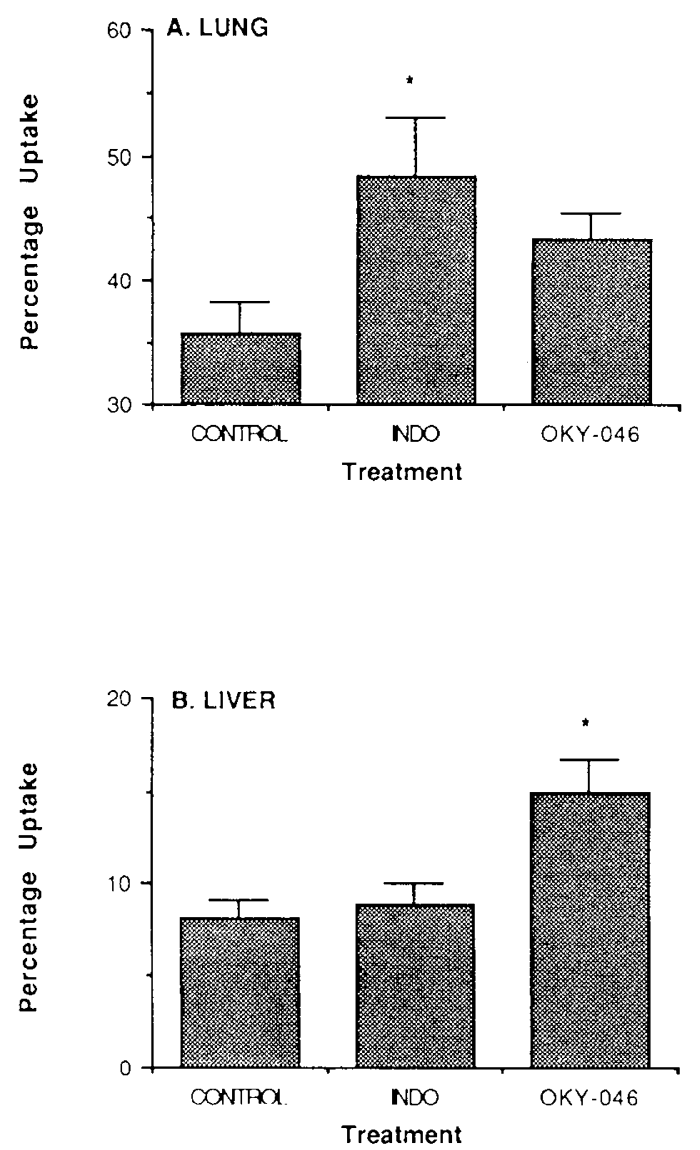

Fig. 2. Distribution of "'indium-labeled GBS into lungs (panel $A$ ) and livers (panel $B$ ) of control $(n=7)$ piglets and piglets pretreated with either indomethacin $(1 \mathrm{mg} / \mathrm{kg}, n=6)$ or OKY-046 $(10 \mathrm{mg} / \mathrm{kg}, n=5)$. Bacterial distribution, calculated as described in Materials and Methods, was determined 45 min after termination of a 15-min infusion of GBS. Note that the scales of the vertical axes differ between panels $A$ and $B$. $*=$ Significantly different from control group at $p<0.05$.
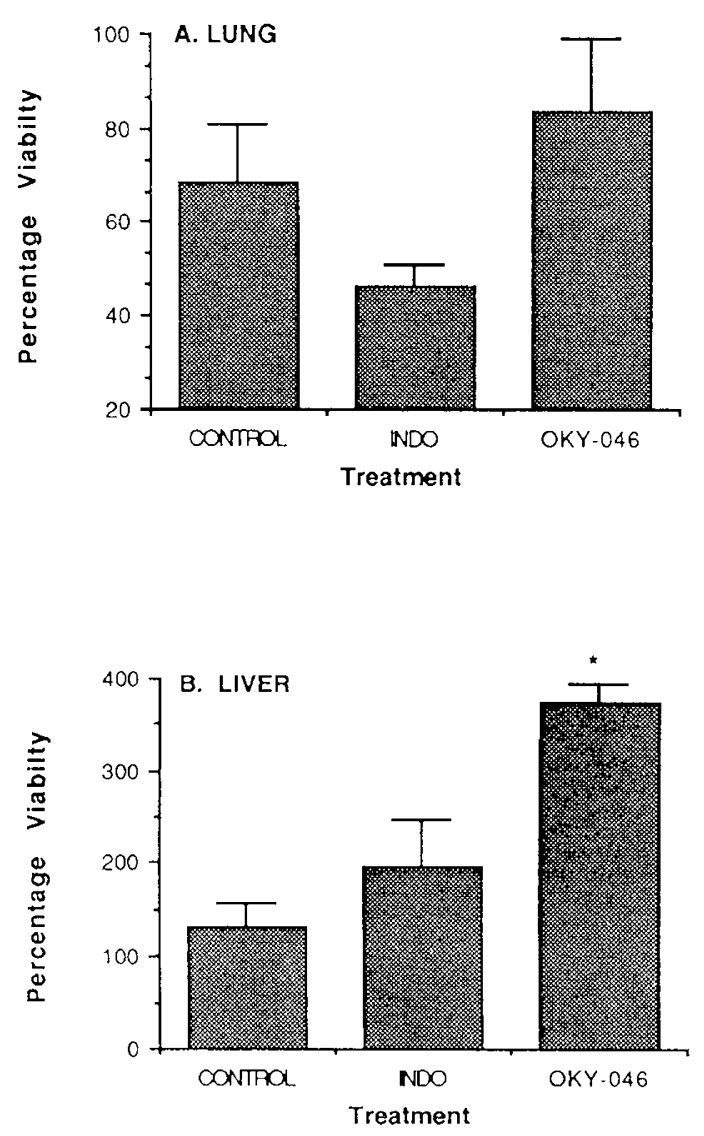

Fig. 3. Viability of "'indium-labeled GBS into lungs (panel $A$ ) and livers ( panel $B)$ of control $(n=7)$ piglets and piglets pretreated with either indomethacin $(1 \mathrm{mg} / \mathrm{kg}, n=6)$ or OKY $-046(10 \mathrm{mg} / \mathrm{kg}, n=5)$. The percentage of bacterial viability, calculated as described in Materials and Methods, was determined $45 \mathrm{~min}$ after termination of a 15 -min infusion of GBS. Note that the scales of the vertical axes differ between panels $A$ and $B .{ }^{*}=$ Significantly different from control group at $p<$ 0.5 .

related pulmonary hypertension, impairs bactericidal activity directed against GBS in intact piglets. We reasoned that if prostaglandin $\mathrm{H}$ synthase-derived oxygen radicals were a significant component of the microbicidal mechanism, then indomethacin would augment bacterial viability. In contrast to our expectations, we found that indomethacin failed to increase either lung or liver bacterial viability. In fact, a trend toward the opposite response was noted; bacterial viability tended to be reduced in lungs from indomethacin-treated animals. As reported by others (e.g. Ref. 1), indomethacin prevented the hypertensive response to GBS, thus confirming efficacy of the drug to inhibit prostaglandin $\mathrm{H}$ synthase. From these observations we conclude that prostaglandin $\mathrm{H}$ synthase-derived oxygen-free radicals do not contribute significantly to bactericidal activity directed against GBS in intact piglets. Nevertheless, because the oxygen radical burden cannot be directly or accurately measured in either lung or liver, this conclusion must be viewed with some caution. It also is appropriate to note that despite the apparent lack of involvement of cyclooxygenase-derived oxygen-free radicals, the bactericidal role of other oxygen radical-generating pathways of arachidonic acid metabolism, including lipoxygenase and cytochrome P-450 $(9,10)$, cannot be excluded on the basis of the present experiments.

In contrast to its lack of impact on lung bacterial viability, indomethacin was associated with an increase in pulmonary deposition of GBS. This favorable combination of increased pulmonary bacterial deposition, in concert with a tendency for increased microbicidal activity, suggests that the impact of indomethacin, and (perhaps) other prostaglandin $\mathrm{H}$ synthase in- 
hibitors on host microbial defense mechanisms, will not present serious obstacles to the use of such agents in septic neonates with pulmonary hypertension. Nevertheless, at least two caveats should be emphasized: First, the impact of indomethacin on host bacterial defense could be fundamentally different in species whose cellular microbicidal mechanisms differ from those of piglets. In this context, relative to piglets, human lungs exhibit a low density of pulmonary intravascular macrophages (13), cells that may play a central role in clearance of intravascular bacteria $(6,14)$. Second, other pharmacologic aspects of prostaglandin $\mathrm{H}$ synthase blockade, particularly its impact on the ductus arteriosis, must be considered as this therapeutic strategy is explored.

Although both indomethacin and OKY-046 prevent GBSinduced pulmonary hemodynamic alterations, ostensibly through inhibition of thromboxane synthesis, there are reasons to suspect that they might have divergent effects on host microbicidal mechanisms. For example, although prostaglandin $\mathrm{H}$ synthase activity is associated with substantial superoxide anion generation, this does not occur with thromboxane synthase (8). Indomethacin, but not OKY-046, might be expected to alter oxygen radical-mediated bacterial killing. Inhibition of prostaglandin $\mathrm{H}$ synthase also has been shown to redirect archidonic acid metabolism to favor synthesis of lipoxygenase products (15); this shift does not likely occur with thromboxane synthase inhibition. An increased burden of lipoxygenase products, which occurs with indomethacin but not OKY-046, could augment recruitment of phagocytes to the lung and thereby increase pulmonary entrapment and killing of bacteria independent of hemodynamic changes. A comparison between the effects of indomethacin and OKY-046 could thus provide information on the relative contribution of hemodynamic and nonhemodynamic factors as determinants of pulmonary microbicidal activity in septic piglets.

Indomethacin increased pulmonary bacterial deposition and tended to decrease bacterial viability, whereas OKY-046 failed to change pulmonary bacterial deposition and tended to increase viability, yet both agents prevented the pulmonary hypertensive response. One explanation for the disparate effects on bacterial distribution is that these agents have divergent actions on blood flow distribution, with pulmonary blood flow increased by indomethacin but not by OKY-046. Counter to this possibility, a recent preliminary report indicates that indomethacin fails to alter cardiac output in anesthetized piglets, at least over a $1-\mathrm{h}$ period corresponding to the duration of the present study (16). The effects of OKY-046 on cardiac output and organ blood flow in infant animals have not, to our knowledge, been reported. A second explanation for the divergent effects of indomethacin and OKY -046 on bacterial deposition and killing may be related to different actions on arachidonic acid metabolism. We speculate that indomethacin may redirect arachidonic acid metabolism to favor increased synthesis of leukotriene $B_{4}$ and other lipoxygenase products that, in turn, recruit additional phagocytes to the lung and/or "prime" these cells for the antimicrobial response directed against GBS (17). Numerous additional experiments will be needed to resolve this hypothesis.

A surprising observation in the present study is that OKY-046 was associated with substantial increases in hepatic bacterial deposition and viability. As alluded to previously, such an alteration could be ascribed in part to changes in hepatic blood flow associated with thromboxane synthase inhibition; additional studies will be required to address this issue. The overall consequences of the OKY-046-induced increases in hepatic GBS deposition and viability are difficult to assess. In the infant piglet, hepatic bacterial deposition is relatively modest, ranging from about 40 to $8 \%$ in our series of studies $(5,6,18)$. The efficacy of bacterial killing also is somewhat less in the liver than in the lung $(5,6,18)$. Consequently, impaired hepatic bacterial clearance associated with OKY-046 might not greatly increase the risk of sepsis in infant piglets and, perhaps, in other species in whom hepatic bacterial clearance is a modest component of the integrated defense mechanism. However, in species such as humans, in whom hepatic bacterial clearance mechanisms predominate over other organs in most instances (19), the effect of OKY-046 might be significant. At present, we have no cogent explanation for impairment of hepatic bacterial clearance by OKY-046. Both the consequences and mechanism of these effects of OKY-046 will require additional study.

In summary, results of the present study indicate that indomethacin fails to impair pulmonary bacterial clearance of GBS in the infant piglet; augmented pulmonary bacterial deposition and a tendency toward enhanced bacterial killing were noted. These observations suggest that prostaglandin $\mathrm{H}$ synthase-derived oxygen radicals do not contribute to pulmonary microbicidal activity directed against GBS. In addition, keeping in mind the difficulties in extrapolation from the laboratory setting to human disease, it seems unlikely that exploration of prostaglandin $H$ synthase inhibition as a strategy for management of pulmonary hypertension in septic neonates will be hampered by impairment of oxygen radical-dependent host microbial defense mechanisms.

\section{REFERENCES}

1. Runkle B, Goldberg RN, Streifeld MM, Clark MR, Buron E, Sctzer ES, Bancalari E 1984 Cardiovascular changes in group B streptococcal sepsis: relationship to prostacyclin and thromboxane $A_{2}$. Pediatr Res 18:874-878

2. Truog WE, Sorenson GK, Standaert TA, Redding GJ 1986 Effects of a thromboxane synthesis inhibitor, damzegrel (UK 38,485) on pulmonary gas exchange and hemodynamics in neonatal sepsis. Pediatr Res 20:486-491

3. Gibson RL, Truog WE, Redding GJ 1988 Thromboxane associated pulmonary hypertension in three types of gram positive bacteremia in piglets. Pediatr Res 23:553-556

4. Shook LA, Pauly TH, Marple SL, Horstman SL. Tai H-H, Bowdy BD, Gillespie MN 1990 Group B streptococcus promotes oxygen radical-dependent thromboxane accumulation in young piglets. Pediatr Res 27:349-352

5. Bowdy BD, Marple SL, Pauly TH, Coonrod JD, Gillespic MN 1990 Oxygen radical-dependent bacterial killing and pulmonary hypertension in piglets infected with group B streptococcus. Am Rev Respir Dis 141:648-653

6. Bowdy BD, Aziz SM, Marple SL, Yoneda K, Pauly TH, Coonrod JD, Gillespie MN 1990 Organ-specific disposition of group B streptococci in piglets: evidence for a direct interaction with target cells in the pulmonary circulation. Pediatr Res 27:344-348

7. Weiss SJ, LoBuglio AS 1982 Biology of disease. Phagocytic generated metabolites and cellular injury. Lab Invest 47:5-18

8. Kontos HA 1987 Oxygen radicals from arachidonate metabolism in abnormal vascular response. Am Rev Resp Dis 136:474-477

9. Kukreja RC, Kontos HA, Hess MA, Ellis EF 1986 PGH synthase and lipoxygenase generate superoxide in the presence of NADH or NADPH. Circ Res 59:612-619

10. Kuthan RC, Ullrich V 1982 Oxidase and oxygen function of the microsomal cytochrome P450 monoxygenase system. Eur J Biochem 126:548-588

11. Kubo K, Kobayashi $\Upsilon 1985$ Effects of OKY-046, a selective thromboxane synthetase inhibitor, on endotoxin-induced lung injury in unanesthetized sheep. Am Rev Respir Dis 132:494-498

12. Coonrod JD, Marple S, Holmes GP. Rehm SR 1987 Extraccllular killing of inhaled pneumococci in rats. $\mathrm{J}$ Lab Clin Mcd 110:753-766

13. Dehring DJ, Wismar BL 1989 Intravascular macrophages in pulmonary capillaries of humans. Am Rev Respir Dis 139:1027-1031

14. Winkler GC 1988 Pulmonary intravascular macrophages in domestic animal species: review of structural and functional properties. Am J Anat 181:217234

15. Robinson DR, Skoskiewicz M, Bloch KJ, Castorena G, Hayes E, Lowenstein E, Melvin C, Michelassi F, Zapol WM 1986 Cyclooxygenase blockade elevates leukotriene $\mathrm{E}_{4}$ production during acute anaphylaxis in sheep. $\mathrm{J}$ Exp Med 163:1509-1517

16. Dyess DL, Peeples GL, Marble KT, Ardell JL, Powell RW, Ferrara JJ 1991 The effect of indomethacin on blood flow distribution in the neonatal pig. FASEB J 5:Al140

17. Bender JG, McPhail LC, VanEpps DE 1983 Exposure of human neutrophils to chemotactic factors potentiates activation of the respiratory burst enzyme. J Immunol 130:2316-2323

18. Pauly TH, Aziz SM, Sandefer E, Gillespie MN 1990 Disposition kinetics of "Indium-labeled group B streptococcus and neutrophils in the lungs of infant piglets. Clin Res 38:927A(abstr)

19. Bencerraf B, Sebestyen M. Schlossman S 1959 A quantitative study of the kinetics of blood clearance of $\mathrm{P}^{32}$-labeled Escherichia coli and staphylococci by the reticuloendothelial system. J Exp Med 1 10:27-48 